\title{
Comparative Study of Methods: GTM and CLT
}

\author{
Pooja Kalia \\ Asst.Prof.in English Khalsa college Amritsar
}

\begin{abstract}
Language learning is a complex activity. It is a fact that a teacher cannot learn on behalf of learners but can only help to create opportunities in the class. A language-learning classroom tends to run much differently from a typical lecture study classroom. It is worthwhile for the teacher to keep in mind various approaches rather than a specific method. Unless we gear our material, approach and syllabus to the needs of the class, we cannot open up new doors for the students. But the irony is the countries where English is mothertongue, a lot of research is done on English Language Teaching whereas in India, where we really face big problems on ELT, there is hardly any research on it. The history of language teaching presents a fascinating variety of methods. The method that works well with one learner may not work with another. Again, different methods may be appropriate to different contexts. If we start searching for the perfect method or the ideal solution to the problems of language learning, we are bound to fail. No method is intrinsically good or bad; it is either well used or badly used. Every method needs to be tailored to the local situation and the context of teaching. There is no single fool proof method, as it were. It is left to the sound practical common sense of the teacher to discover in what circumstances for what purpose which method is most effective. One thing which is of utmost importance is to clear our objectives. The objective of teaching language is not only to make the students clear their examination as it is mostly considered but its real aim is to make them use that language for practical purposes.
\end{abstract}

Keywords: Language learning class room, approaches, methods, English language teaching (ELT), lecture style classroom.

\section{Introduction}

An approach to English language teaching that has been almost universal, most traditional \& historically evolved has come to be called GTM i.e. Grammar Translation method. It was also known as the Prussian method in the United States of America. This method was the brainchild of German Scholarship like Seidenstucker Kare Plotz, H.S. Ollendorf and Johann Meidinger whose principal aim was to make language learning easier (Richards \& Rodgers, 2001, p.3).1

In the teaching of English, this method has enjoyed a great reputation in the past. Since this method is also known as translation method, its very name indicates that the target language is taught by translating it into mother tongue. Each word, phrase or sentence of English is taught by translating it into mother tongue. The philosophy behind this method is that foreign language can be best taught \& learnt through translation. In GTM, written form is given upper hand \& no care is taken of the spoken aspect of language. It is based on the assumption that all the languages have fundamentally the same grammar and by the comparative study of the grammar of the mother tongue (Ll) and that of foreign language (L2), the latter can be understood and mastered easily and also the structure of English language can be best learnt. This method demands very good crammers and not good learners who can memorize several words and rules. The most important demerit of this method is that mother tongue is mostly used in the classroom, rather than the language which learners are supposed to learn. Mother tongue acts as a major obstacle in their way to learn a foreign language, which also prevented the learner from developing confidence to communicate in English.

It is not only difficult but rather quite impossible to cut the umbilical cord between the learner \& the mother tongue. Our ultimate motive is that learner should not depend on the crutches of mother tongue while expressing them in foreign language. Learner must think in English so as to express the ideas in English. The products of GTM were usually tongue-tied, as they preferred to remain silent rather than to expose their ignorance because through this method the learners don't attain the fluency of speech. No doubt, translations are helpful but not their excess usage. In this method, there is an overemphasis on form with the virtual exclusion of meaning.

In this method, the medium of instruction is student's native language. It is used to explain new items and to make comparisons between foreign and student's native language. Accuracy rather than fluency is stressed upon in this method. Over emphasis on accuracy leads to pointing out of learner's mistakes in excess which de-motivates the learner. Teachers stressing on accuracy do not let the learner complete the sentence \& 
keep pointing out their mistakes every now \& then. Moreover, this method emphasizes the dominance of mother tongue in the teaching of English. Learning the language is not like walking on a straight road but actually the road of language is full of diversions. In this method, form is stressed upon but in reality meaning is the guiding force. Learning the language through this method was a tedious experience because learners had to memorize rules, endless list of grammar rules, vocabulary items \& structures. This method emphasized grammar in an organized manner; grammar of rules was taught but not the grammar of arranging words in a meaningful way.

Grammar translation method dominated European \& foreign language teaching from the 1840s to the 1940s and it is still widely used in some parts of the world (Richards and Rodgers, 2001, p.5) 2. Even today when a hundred linguistically sound methods are being propagated, GTM still seems to have its relevance.It is one of the most convenient methods to use in big classes.

The merits of GTM must be illustrated so that we can probe deeper and in a better way. In this method, the teacher can at once make the students understand the meaning of any line or word of English by translating it into mother tongue thereby saving the time. It also helps the teacher in testing whether the students have understood the foreign language or not. It is an easy method because here we proceed from the known to the unknown that facilitates teaching-learning process. Therefore; it forms a strong memory bond between the foreign symbols and the native words. This method is very reliable for giving students practice in reading with understanding.

The whole method consisted of a movement from explanation and analysis to writing answers to questions. Dictation formed a very important part of language teaching. This method involves a progressive movement from written forms to spoken forms. The letters of the English alphabet, for instance, formed the basis of learning English words. The sound came secondary and dependent on spellings. Pupils learnt the spellings much before they picked up the spoken form or the actual pronunciation of words. Thus, the L2 learner of English was dependent on spellings for their pronunciation.

Like the two faces of the coin, GTM also has another face full of demerits which cannot be ignored.

The various weaknesses of this method are: -

$>$ The greatest weakness of this method is that the whole approach to English is through translation. In the English text, there are hundreds of words for which there are no appropriate equivalents in the Indian language e.g. drawing room, signal, and key in music etc. The students tend to think in mother-tongue and then translate it into English. Sometimes spirit of sentences or lines is not caught up by translation work which in turn leads to funny expressions. Moreover, translation work is always approximate so one does not get at the reality of learning the language.

$>$ No doubt, translations are helpful but not their excess usage. Students of this method get used to noting down the equivalent words in mother-tongue. This gives them a wrong notion that a word has only one meaning. They fail to learn the use of single word in different contexts.

$>$ The differences of the structure of English when compared with that of the Indian languages make wordfor-word translation futile and very often absurd e.g. 'a' and 'the' in 'a man' and 'the man' are not translatable in the mother-tongue (Sachdeva, p.61) 3.

$>$ The complex English tenses cannot be rendered into the simple tenses of the Indian languages. Some of these tenses have no equivalents in the Indian languages. Again, there is no passive voice in the Indian languages. Most of the English prepositions are different from those of the mother-tongue such as 'on the move', 'on the committee', 'angry with', 'kind to' etc. We have no appropriate equivalent for many prepositional phrases; such as, 'in the way', 'on the way', 'by the way' etc.

$>$ It does not take into consideration all the four skills of language: listening, speaking, reading and writing. It provides practically no chance for drill in the aural-oral skills. The spoken aspect of the language is almost completely neglected. That is why the products of GTM are always tongue-tied; since through this method the learners don't attain the fluency of speech.

$>$ The language learnt, thus, is of little practical use to the students.

$>$ The students tend to break up sentences into words. They translate by taking up words. It puts a heavy check on their speed of reading.

$>$ This method fails to capture the delicate shades of meaning, local color and secondary meaning. The subtle differences in the meaning of the words, happiness, joy, gladness, rapture, trance, ecstasy etc., are not made clear in the mother-tongue.

$>$ Word-for-word translation often gives a meaningless jumble of words, e.g. 'It rained cats and dogs;' 'by hook or by crook' etc. when translated into the mother tongue gives absurd expressions.

$>$ Moreover, this method cannot provide an insight into foreign idioms such as 'to boycott', 'a man' of straw', 'Man Friday', 'an elbow room' etc.

$>$ This method does not give opportunities for silent reading as the habit of word- for-word translation hinders the rapid absorption of large word groups which is the essence of reading.

$>$ Our ultimate goal is that the pupil must reach a stage, when he is able to speak and write English without 
the help of translation. He must be able to speak and write English without help of translation. The fundamental weakness of translation is that it prevents and retards the pupil from thinking in English. A pupil, who is constantly framing his thoughts in the mother-tongue and then converting them into English, will never be able to speak and write English without the help of translation.

$>$ Psychologically this method is wrong. It is an unnatural method. It ignores the fact that in learning language the first step is to learn the spoken language and to practice it through oral speech language. This method does not make use of the ear in language-learning. The use of the eye and the disuse of the ear seriously affect the efficiency and usefulness of this method.

$>$ By grammatical way of teaching the language, the lessons become dull and dry. The pupils do not take an active part. The teacher is active and in a commanding position while the pupils are passive. The pupils remain absent-minded but still pretend to be listening to the teacher. Pupils are burdened in this method. GTM continues to be an asylum of inexpert, un-resourceful, incompetent, disillusioned and demoralized teacher who are not prone to exert their creative intelligence \& imagination in making classroom teaching a rewarding experience.

$>\quad$ It gives rise to what is called, 'Babu English'. We often hear students speaking: "why are you angry from me"? "He went on the station", "He is kind on me" etc.

$>\quad$ It wastes a lot of time which can be utilized profitably in doing some other useful work in English. Those who taught English through GTM largely did not handle English the way needed as there are enough loopholes to the use of English in the classroom under the shade of this method.

Thus, to conclude, it can be said that this method has many disadvantages but this does not mean that translation is bad; rather it is an important exercise in composition. Translation is, thus, a powerful aid in the interpretation of foreign language, provided it is not used in excess.

GTM has been the most widely practiced method of teaching a foreign language in our colleges. One may, however, say that in the past few decades great many changes have taken place in English language teaching methodology in India (Yule, 1985) 4. The followers of this method must not forget that, "if we wish to speak well, we must murder the language first."5.

\section{Communicative Language Teaching}

The other important approach of English Language Teaching is CLT. Communicative language teaching rose to prominence in the 1970's and early 1980's as a result of many disparate developments in both Europe and US. Until late 1960s it was the situational Language Teaching (SLT) that dominated the ELT scene in Britain. When communicative language (CLT) was first developed in the 1970s, it was widely seen as the definitive response to the shortcomings of previous approaches and the communicative needs of a globalized world. They saw the need to focus in language teaching on communicative proficiency rather than mere mastery of structures. Both American and British proponents now see it as an approach and not a method that aims to (Richard and Rodgers 2001) 6.

a) make communicative competence the goal of language teaching and

b) develop procedures for the teaching of the four language skills that acknowledge the interdependence of language and communication.

The communicative approach can be traced to the work of Chomsky in the 1960s, when he advanced the two notions of 'competence' and 'performance' as a reaction against the prevalent audio-lingual method and its views.

CLT which is an approach to the teaching of second and foreign languages emphasize interaction as both the means and ultimate goal of learning a language. The communicative approach is based on the idea that learning language successfully comes through having to communicate real meaning. When learners are involved in real communication, their natural strategies for language acquisition will be used and this will allow them to learn to use the language. So its goal is to make use of real life situations that necessitate communication.

CLT has left its doors open for a great variety of methods and techniques. There is no single text or authority on it, nor any single model that is universally accepted as authoritative. By and large, it uses materials and utilizes methods that are appropriate to a given context of learning. CLT does not adhere to one particular theory or method. It draws its theories about learning and teaching from wide range of areas such as cognitive science, educational psychology, and second language acquisition (SLA).

The CLT teacher's primary role is thus to organize the classroom as a setting for communication and communicative activities. In CLT, the traditional procedures are not neglected; rather they are reinterpreted and extended.

From the existing literature on CLT, Richards and Rodgers (2001) 7 glean the following as the main characteristics of the communicative view of language.

1. Language is a system for the expression of meanings.

2. The primary function of language is for interaction and communication. 
3. The structure of language reflects its functional and communicative uses.

4. The primary units of language are not merely its grammatical and structural features, but categories of functional and communicative meaning as exemplified in discourse (Rodgers, 2015) 8.

There are many advantages in teaching according to the communicative approach:-

1. CLT is a holistic approach. It does not focus only on the traditional structural syllabus. It takes into consideration communicative dimension of language.

2. CLT provides vitality and motivation within the class.

3. CLT is a learner centered approach. It capitalizes on the interests and needs of the learner.

4. In a world where communication of information and technology has broken new considerable ground, CLT can play an important role in education.

5. Learning a language is interactive, co-operative, learner-centered and content based but the approach does not mean that learning a second language involves just conversation 9 .

\section{Criticism}

1. The various categories of language functions are overlapping and not systematically graded like the structures of language.

2. The communicative approach focuses on the use of language in everyday situations, or the functional aspects of language, and less on formal structure. There must be a certain balance between the two. It gives priority to meanings and rules of use rather than to grammar and rules of structure. This may result in negative consequences in the sense that important structure and rules would be left out.

3. A major principle underlying this approach is its emphasis on learner's needs and interests. This implies that every teacher should modify the syllabus to fit the needs of the learners.

4. The requirements are difficult. Not all classrooms can allow for group work activities and for teaching aids and materials.

5. The approach gives priority to meanings and rules of use rather than to grammar and rules of structure 10 .

6. Inspite of criticism, CLT has gained widespread acceptance in the world of language study. CLT can succeed, as long as teacher don't completely reject the need for the structure provided by grammar. CLT, in the hands of a balanced teacher, can bring new life and joy to the classroom.

\section{The Challenges of Implementing CLT}

Practical challenges are reported from numerous countries when teachers have been asked to implement CLT in primary and secondary schools, where classes are often large and resources are limited. These challenges are:-

1. Difficulties with classroom management especially with large classes, and teachers' resulting fear that they may lose control.

2. New organizational skills required by some activities such as pair or group work.

3. Students' inadequate language proficiency, which may lead them to use the mother tongue rather than trying to 'stretch' their English competence.

4. Excessive demands on teachers' own language skills, if they themselves have had limited experience of communicating in English.

5. Common conceptions that formal learning must involve item-by-item progression through syllabus rather than the less observable holistic learning that occurs in communication.

6. Common conceptions that the teacher's role is to transmit knowledge rather than act as a facilitator of learning.

7. Resistance from students and parents, who fear that important examination results may suffer as a result of the new approach.

\section{Comparative Analysis}

Every method has its own strengths and weaknesses. In GTM, learning English began with reading and writing whereas in CLT, interactive processes of communication received priority. Translation into the mother tongue as a learning device is thrown out of the foreign language teaching classroom. But CLT is based on the idea that learning language successfully comes through having to communicate real meaning. When learners are involved in real communication, their natural strategies for language acquisition will be used, and this will allow them to learn to use the language.

In GTM classes are taught in the student's mother-tongue, with little active use of target language whereas in CLT, the focus is given on communication and students are allowed to experiment with the language $\left(\mathrm{L}_{2}\right)$ and in turn learn the language automatically. The focus is given on identifying learner's communicative needs and classroom activities. In GTM textbooks primarily consisted of list of vocabulary and rule explanations. By and large, students were engaged in translation activities only. Little oral proficiency would 
result from GTM, and students often were expected to go abroad and immerse themselves to become fluent speakers. Whereas in CLT care is taken that language teaching should be learner-centered, creating opportunities for learners to use language with communicative approach. There is much greater room for individual interpretation and variation than most methods permit. CLT appeared at a time when British language teaching was ready for paradigm shift. CLT appealed to those who sought a more humanistic approach to teaching, one in which the interactive processes of communication received priority.

\section{Conclusion}

There is no single 'best' and final way of teaching foreign language or second language. A successful teacher will not limit oneself to one method only. A method which is appropriate with one class on one occasion will not necessarily suit the same class at another time. If we respect our students and plan our curriculum to suit the needs of the class, there won't be much difficulty.

\section{Works Cited}

[1]. Jack C. Richards and Theodore S. Rodgers, Approaches and Methods in Language Teaching: A Description and Analyses. Cambridge University Press, 2001, p.3. Ibid. p.5.

[2]. Sachdeva, M.S. A New Approach to Teaching of English in India, Tandon/Vinod Publications, p.61.

[3]. Yule, George, the Study of Language: An Introduction, Cambridge University Press, 1985. www.quotegarden.com.

[4]. Jack C. Richards and Theodore S. Rodgers, Approaches and Methods in Language Teaching: A Description and Analyses. Cambridge University Press, 2001.

[5]. Ibid.

[6]. Rodgers, T. (2015), Language Teaching Methodology. Online Resource (http://www.calorg/resources/digest/rodgers.html), September 2016.

[7]. www.googleweblight.com.

[8]. www.myenglishpages.com. 